\title{
Quantifying the incidence and cost of acute gastrointestinal illness in Sweden, 2013-2014
}

\section{EDELSTEIN*, H. MERK, C. DEOGAN, A. CARNAHAN AND}

\section{A. WALLENSTEN}

Public Health Agency of Sweden, Solna, Sweden

Received 6 November 2015; Final revision 12 February 2016; Accepted 16 February 2016;

first published online 11 March 2016

\section{SUMMARY}

In Sweden, acute gastrointestinal illness (AGI) incidence, severity, impact on productivity, related healthcare usage and associated costs are not ascertained. We measured these in 2013-2014 using a population-based cohort reporting weekly. We defined AGI as $\geqslant 3$ episodes of loose stools or vomiting/24 h; or loose stools or vomiting with $\geqslant 2$ other gastrointestinal symptoms. After each AGI episode, we collected information about perceived severity, healthcare use and absenteeism. We calculated incidence rates, AGI absenteeism and costs comprising direct healthcare costs and productivity loss due to work/school absenteeism. A total of 3241 participants reported 1696 AGI episodes [incidence 360/1000 person-years, 95\% confidence interval (CI) 326-395; highest in the $<5$ years age group]. In the $<5$ years age group, $31 \%$ of episodes were perceived as mild, $61 \%$ as moderate and $8 \%$ as severe; $9 \cdot 4 \%$ led to primary-care consultations, and $1.4 \%$ to hospital admissions. In the $\geqslant 5$ years age group, $18 \%$ of episodes were perceived as mild, $64 \%$ as moderate and $18 \%$ as severe; $6.4 \%$ led to primary-care consultations, and $1.9 \%$ to hospital admissions. AGI caused 8891000 days of absenteeism (95\% CI $6009000-12780000)$. AGI cost $€ 1005885000$ (95\% CI 754309 000-1 257195000 ) nationally for the year. In Sweden, a minority of cases perceive AGI as a mild illness. AGI is a burden on the healthcare system and causes productivity loss, with high costs. Countries may consider these estimates when prioritizing health interventions.

Key words: Cohort studies, economics, gastroenteritis, incidence, Sweden.

\section{INTRODUCTION}

Acute gastrointestinal illness (AGI) is commonly caused by infection with norovirus, sapovirus, rotavirus, Campylobacter and E. coli [1]. Most AGI is of low severity, short duration, and requires no clinical intervention. Its social and economic burden is high due to associated usage of healthcare services and work and school absenteeism [2]. Knowing the AGI community incidence adds public health value by

\footnotetext{
* Author for correspondence: Dr M. Edelstein, 61 Colindale Avenue, London NW9 5EQ, UK.

(Email michael.edelstein@doctors.org.uk)
}

enabling assessment of the associated economic and healthcare burden, evaluation of control strategies and interpretation of surveillance data [1]. However, routine surveillance alone cannot estimate AGI community incidence because the small proportion of AGI cases using the healthcare system differs from the wider burden of AGI in terms of underlying organisms, severity and socio-demographic characteristics of affected individuals [3, 4]. Previous estimates of AGI community incidence have relied on cohort studies of populations registered with general practices (GPs) $[1,5]$ or on retrospective studies [6-9]. These studies have found community incidences per 1000 
person-years ranging from 274 in 2008-2009 in the UK [1] and 283 in The Netherlands in 1999 [5] to 1400 in 2009 in Denmark [9], and AGI-related GP consultation rates between $6 \cdot 4 \%$ and $30 \cdot 4 \%[1,6,7,10]$, and hospitalization rates between $2 \%$ and $4 \cdot 6 \%[6,7,10]$. AGI-associated productivity loss and healthcare costs were estimated at CAN\$113.70 (€75) per case in Canada in 2011 [11] and AUD 150 (€104) per case in Australia in 2006 [12]. However, variations in AGI incidence, healthcare costs [13] and average salaries combined with different methods used to calculate costs make it difficult to extrapolate or compare AGI cost to society from one country to another.

In Sweden, one previous retrospective study attempted to measure community incidence of AGI. It estimated AGI incidence at 310/1000 person-years in 2009 [14], without assessing the AGI costs to society. In 2013, The Public Health Agency of Sweden invited 34970 Swedish residents up to the age of 85 years, selected using random age-stratified sampling to join Hälsorapport, a prospective, population-based cohort with several objectives, among which included measuring the incidence of a range of symptoms in the Swedish population via weekly health status reports. The sample size was calculated on an expected $10 \%$ response rate, in line with previous participatory surveillance cohorts in Sweden and other European countries [1]. The cohort comprised 3241 individuals, of which 1479 were children $(45 \cdot 6 \%)$ aged $<5$ years and 1729 females (53\%). On average, 2619 participants reported their health status each week (range 2007-2851). Further information on the cohort can be obtained by contacting the authors, and will also be available in a future publication. Using Hälsorapport, we aimed to estimate the community incidence of domestically acquired AGI in Sweden over a year as well as its perceived severity, associated healthcare usage and economic impact.

\section{METHODS}

\section{Reporting symptoms}

Between week 46, 2013 (week commencing 11 November), and week 47, 2014 (week commencing 17 November), we emailed all participants weekly, asking them (or their legal guardians for children aged $<16$ years) to report which symptoms, if any, they experienced during the previous week (Fig. 1). We also collected information regarding recent travel. For any given week, we defined a participant as active if he/she reported at least once in the 3 weeks preceding the week of interest. In order to minimize reporting bias (participants reporting only when they experienced symptoms), we only included AGI episodes from active participants in the incidence estimation. We therefore excluded the first 3 weeks from the analysis. Starting week 50, 2013 (week commencing 9 December), every time a participant reported symptoms, we sent a follow-up email questionnaire in the third week after the report (Fig. 1) to collect information regarding perceived severity of illness, using a scale from 1 (very mild) to 6 (very severe). The delay between participants reporting symptoms and receiving the severity questionnaire was based on time required to identify participants eligible for the questionnaire, and to send it. We grouped 1 and 2 as mild disease, 3 and 4 as moderate, and 5 and 6 as severe. We also asked about symptom duration, symptom-related GP and hospital attendance, and number of AGI-related days taken off work or school. We compared cases perceived as mild and severe in terms of average symptom duration and proportion of healthcare attendance, using $\chi^{2}$ tests.

\section{AGI case definition}

We defined an AGI case as having $\geqslant 3$ loose stools in $24 \mathrm{~h}$ or vomiting $\geqslant 3$ times in $24 \mathrm{~h}$ or loose stools with $\geqslant 2$ additional symptoms in $24 \mathrm{~h}$ or vomiting with $\geqslant 2$ additional symptoms in $24 \mathrm{~h}$. The additional symptoms could be loose stool, vomiting, abdominal pain, fever, nausea, blood in the stool, or mucus in the stool. This definition has been used in previous AGI incidence studies [5].

\section{Calculating AGI incidence and severity}

We included each week a participant reported between week 49, 2013 (commencing 2 December) and week 47, 2014 (referring to the period between week 48, 2013 and week 46, 2014) in the total person-time at risk and counted AGI reports. Periods of inactivity were not counted towards person-time at risk. We excluded episodes where symptoms were reported within 10 days of travelling abroad. If symptoms fitting the AGI case definition were reported more than 1 week in a row with no AGI-free period in between, we counted this as only one episode. We counted reported symptoms fitting the AGI case definition as separate episodes if they were separated by at least one AGI-free week. We age-calibrated 


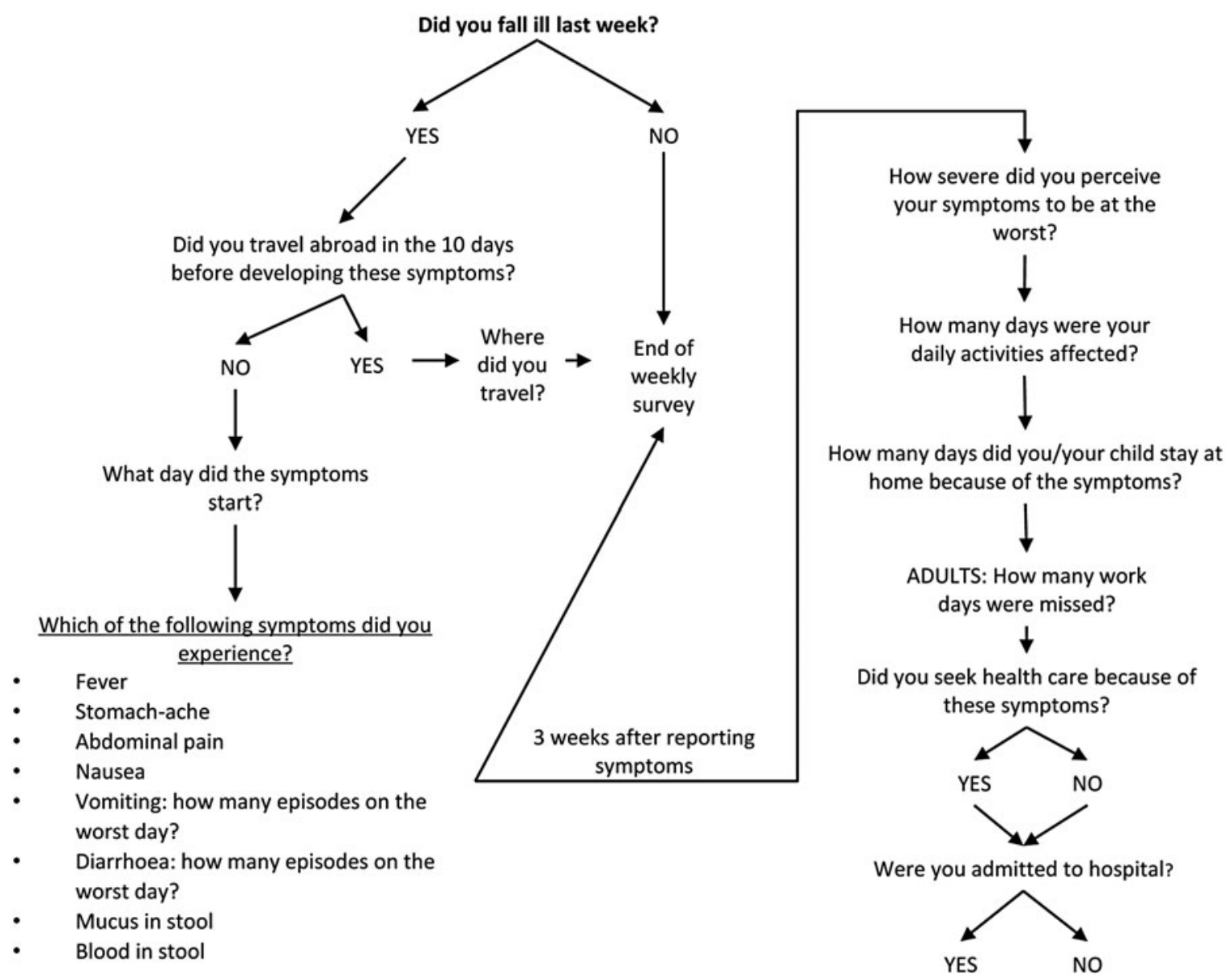

Fig. 1. Symptom and severity reporting algorithm.

[15] all estimates to adjust for the differences in age distribution between the sample and the population, using the 2012 Swedish population estimated by Statistics Sweden (www.scb.se) as the standard population (total estimated population 9555893 ). The calibration method is described elsewhere [15]. We calculated the AGI incidence with 95\% confidence intervals (CIs), overall and within different age groups $(<5,5-14,15-64,65-85$ years).

We estimated the mean duration of an AGI episode and the overall number of days of AGI-related work or school absenteeism, along with $95 \%$ CIs. We measured the proportions of participants attending GP and admitted to hospital for children aged $<5$ years and individuals aged $\geqslant 5$ years. Finally, we estimated the perceived severity of symptoms in these same age groups.

\section{Calculating economic impact}

We based our cost estimate on direct healthcare costs and productivity losses from lost days of work due to acute illness only. We excluded indirect healthcare costs such as transport to or from hospital, and costs attributable to healthcare and productivity losses due to long-term sequelae of AGI episodes.

We defined AGI-associated productivity loss as the time away from paid employment because of one's own AGI symptoms or to care for a participating child with AGI. We valued a day of work, according to the human capital approach [16], as the average yearly Swedish age-specific 2012 income [17] (in 5 -year age bands) plus social fees (employer payroll tax) of $31.42 \%$ [17], divided by the number of working days in a year (Table 1). These income averages reflect the range of occupations individuals are employed in and account for the fact that a proportion of the working-age population is not in full-time paid employment. The age-specific estimates are available for adults aged $\geqslant 20$ years. To estimate the cost of a day off work to care for a child, we used the average cost of a day of work across all age groups (20-64 years). In order to calculate the cost attributable to 
Table 1. Salaries, cost of day off work or school, and number of AGI-related days off school or work, Sweden, 2012

\begin{tabular}{|c|c|c|c|}
\hline $\begin{array}{l}\text { Age } \\
\text { group, } \\
\text { years }\end{array}$ & $\begin{array}{l}\text { Average } \\
\text { yearly } \\
\text { salary (€) }\end{array}$ & $\begin{array}{l}\text { Average cost of } \\
\text { day off school } \\
\text { or work }(€)^{*}\end{array}$ & $\begin{array}{l}\text { Total number of } \\
\text { days off school or } \\
\text { work (week } 48 \text {, } \\
2013 \text { to week } 46 \text {, } \\
2014) \dagger\end{array}$ \\
\hline$<1$ & - & 0 & 0 \\
\hline $1-4$ & - & 174 & 1730707 \\
\hline $5-10$ & - & 174 & 972792 \\
\hline $11-14$ & - & 174 & 298014 \\
\hline 15-19٪ & - & 0 & 1360868 \\
\hline $20-24$ & 13376 & 78 & 519815 \\
\hline $25-29$ & 20878 & 122 & 1023462 \\
\hline $30-34$ & 26884 & 157 & 1022959 \\
\hline $35-39$ & 31900 & 186 & 473553 \\
\hline $40-44$ & 35233 & 206 & 325290 \\
\hline $45-49$ & 36410 & 213 & 485080 \\
\hline $50-54$ & 35475 & 207 & 152852 \\
\hline $55-59$ & 34573 & 202 & 213181 \\
\hline $60-64$ & 33000 & 193 & 312106 \\
\hline$\geqslant 65$ & - & 0 & 0 \\
\hline
\end{tabular}

AGI, Acute gastrointestinal infection.

* The average salary across age groups 20-64 years was used to calculate the cost of a day off work to look after a sick child.

$\dagger$ Parents of children aged $<1$ year were assumed to be on parental leave and we assumed age of retirement at 65 years; therefore individuals aged $<1$ year and $>65$ years did not contribute to days off.

\$ We assumed the 15-19 years age group are mainly in education but can look after themselves when sick; therefore this age group does not have a cost attached but still contributes to days off work or school.

productivity loss at the national level, we estimated the total number of days lost to AGI nationally using age-specific AGI incidence and mean number of days spent at home as a result of AGI (Table 1) and annualized the 51 weeks of data available. We then multiplied the total number of days lost by the value of a work day for each age group. We made the following assumptions: (i) children aged $<1$ year did not cause any productivity loss since they were not eligible for pre-school under Swedish law [18] and one parent would be on parental leave to look after them; (ii) $84 \%$ of children between the ages of 1 and 10 years went to pre-school [19] and thus required one parent to take time off to look after them if sick; (iii) children between the ages of 11 and 14 years could stay home alone at least part of the time and therefore only required one parent to take time off $50 \%$ of the time; (iv) children aged 15 19 years were mainly in full-time education and could stay home alone if sick, and therefore did not contribute to productivity loss [20]; (v) individuals aged $\geqslant 65$ years were retired and therefore did not contribute to productivity loss; and (vi) reported days included non-working and unpaid days such as weekends, which was adjusted for. In order to account for the uncertainty around the total cost of productivity loss, we ran a sensitivity analysis around the number of days off work or school due to AGI, using the upper and lower ends of the calculated AGI incidence CIs.

We calculated the cost attributable to primary-care usage by multiplying the estimated total number of cases attending GP with the average price of a GP consultation $(€ 157)$. To determine the cost attributable to hospital admissions, we estimated the cost of an average acute gastroenteritis-related hospital stay based on diagnosis-related group (DRG) costs which were representative of the national average for Sweden [21, 22]. Acute gastroenteritis DRGs vary by severity (very complicated, complicated, uncomplicated) and age ( $<18$ and $\geq 18$ years, Table 2$)$. We applied these DRG costs to the proportion of patients admitted under each DRG using data from the National Board for Health and Welfare (https:// www.socialstyrelsen.se/statistik/statistikdatabas/drgislutenvard; Table 2). We estimated the average cost of an acute gastroenteritis hospital stay at €2491 using the parameters described in Table 2. Prescription costs were included in the cost of a hospital episode. Prescriptions by GP were considered patient costs and were not included. To account for the uncertainty around the number of GP consultations, we ran a sensitivity analysis around the age-specific AGI incidences, using the upper and lower ends of the calculated CIs.

\section{Power}

Assuming an overall AGI incidence similar to The Netherlands (283/1000 person-years) [5], and $\alpha=$ $0 \cdot 05$, we could estimate AGI incidence with a $95 \%$ CI of $\pm 6 \cdot 6 \%$.

We sought ethical approval. The ethics committee considered this study to be part of routine surveillance activities and therefore did not require specific approval. We used Stata v. 13 (StataCorp., USA) for all statistical analyses. 
Table 2. Parameters used to calculate the cost of an average acute gastroenteritis hospital stay, Sweden, 2012

\begin{tabular}{|c|c|c|c|c|c|c|}
\hline $\begin{array}{l}\text { DRG by severity } \\
\text { and age group }\end{array}$ & $\begin{array}{l}\text { Episode } \\
\text { cost }(€)^{*}\end{array}$ & $\begin{array}{l}\text { Average } \\
\text { length of } \\
\text { stay* }\end{array}$ & $\begin{array}{l}\text { Proportion of total } \\
\text { gastroenteritis } \\
\text { admissions by age } \\
\text { group }(\%)^{*}\end{array}$ & $\begin{array}{l}\text { Weighted } \\
\text { average daily } \\
\text { cost of stay in age } \\
\text { group }(€)\end{array}$ & $\begin{array}{l}\text { Weighted } \\
\text { average length } \\
\text { of stay in age } \\
\text { group }\end{array}$ & $\begin{array}{l}\text { Proportion of age } \\
\text { group in total } \\
\text { population }(\%) \dagger\end{array}$ \\
\hline $\begin{array}{l}\text { Complicated } \\
\text { gastroenteritis } \\
<18 \text { yr (F49C) }\end{array}$ & 2508 & 6 & $19 \cdot 7$ & 402 & $5 \cdot 2$ & $20 \cdot 2$ \\
\hline $\begin{array}{l}\text { Uncomplicated } \\
\text { gastroenteritis } \\
<18 \text { yr (F49E) }\end{array}$ & 1995 & 5 & $80 \cdot 3$ & & & \\
\hline $\begin{array}{l}\text { Very complicated } \\
\text { gastroenteritis } \\
>17 \mathrm{yr}(\mathrm{F} 47 \mathrm{~A})\end{array}$ & 4176 & 18 & 5 & 304 & 8.5 & $78 \cdot 8$ \\
\hline $\begin{array}{l}\text { Complicated } \\
\text { gastroenteritis } \\
>17 \text { yr (F47C) }\end{array}$ & 2928 & 12 & 32 & & & \\
\hline $\begin{array}{l}\text { Uncomplicated } \\
\text { gastroenteritis } \\
>17 \mathrm{yr}(\mathrm{F} 47 \mathrm{E})\end{array}$ & 2046 & 6 & 63 & & & \\
\hline
\end{tabular}

DRG, Diagnosis-related group.

* Obtained from Swedish Board of Health and Welfare.

$\dagger$ Obtained from Statistics Sweden.

Table 3. Age-calibrated AGI incidence rate, by age group, Sweden, November 2013-November 2014

\begin{tabular}{lcclr}
\hline \hline $\begin{array}{l}\text { Age group } \\
\text { (years) }\end{array}$ & $\begin{array}{l}\text { Person-weeks } \\
\text { reported }\end{array}$ & $\begin{array}{l}\text { Reported AGI } \\
\text { cases }\end{array}$ & $\begin{array}{l}\text { Age-calibrated } \\
\text { incidence } \\
\text { rate/1000 person-years }\end{array}$ & $95 \%$ CI \\
\hline$<5$ & 55700 & 1226 & 1111 & $1043-1179$ \\
$5-14$ & 20133 & 193 & 501 & $430-571$ \\
$15-64$ & 40436 & 238 & 333 & $283-384$ \\
$65-85$ & 17324 & 39 & 118 & $81-155$ \\
Total & 133593 & 1696 & 360 & $326-395$ \\
\hline \hline
\end{tabular}

AGI, Acute gastrointestinal infection; CI, confidence interval.

\section{RESULTS}

\section{Incidence}

Over the study period (week 49, 2013 to week 47, 2014), participants reported 133593 person-weeks (2569 person-years) and 1696 domestically acquired AGI episodes between week 48, 2013, and week 46, 2014. There were 734 participants reporting a single AGI episode, 288 reporting two, and 112 reporting $\geqslant 3$ episodes.

The overall incidence rate was $360 / 1000$ personyears (95\% CI 326-395). The highest incidence was in children aged $<5$ years $(1111 / 1000$ person-years, 95\% CI 1043-1179; Table 3). The overall weekly incidence peaked in week 9, 2014 (Fig. 2) (794/1000 person-years, 95\% CI 474-1115). Data underlying Figure 2 are available in Supplementary Table S1.

\section{Severity and burden to society and healthcare}

We received 1513 (89\%) follow-up questionnaires. Of these, $1098(73 \%)$ were for children aged $<5$ years. In this age group, $31 \%$ of the episodes were perceived as mild, $61 \%$ as moderate and $8 \%$ as severe. Of the 435 AGI episodes in individuals aged $\geqslant 5$ years, $18 \%$ were perceived as mild, $64 \%$ as moderate and $18 \%$ as severe. In children aged $<5$ years, $9 \cdot 4 \%$ of AGI episodes led to GP consultation and $1.4 \%$ to hospital admission. Of those aged $\geqslant 5$ years, $6 \cdot 4 \%$ led to GP 


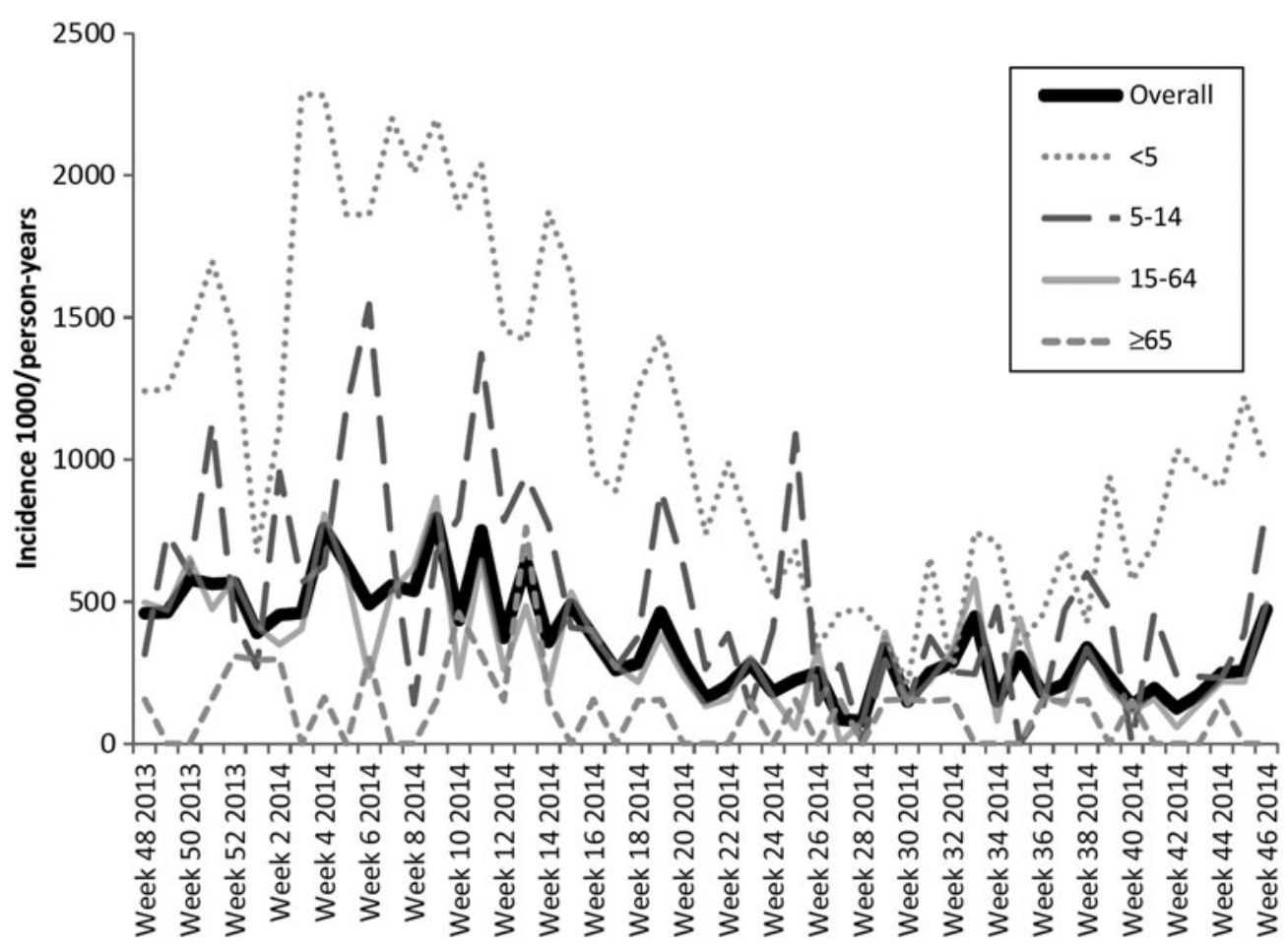

Fig. 2. Weekly acute gastrointestinal illness incidence by age group, Sweden, 2013-2014.

consultation and 1.9\% to hospital admission. An AGI episode lasted a mean of $3 \cdot 4$ days $(95 \%$ CI $3 \cdot 1-3 \cdot 7)$ and the duration was similar across age groups. Episodes perceived as severe lasted 5.8 days (95\% CI $5 \cdot 3-6 \cdot 4)$ on average, whereas episodes perceived as mild lasted a mean of 1.9 days $(95 \%$ CI $1.7-2, P<$ $0 \cdot 001)$. Compared with cases perceived as mild, cases perceived as severe were more likely to report GP and hospital attendance $(13.6 \%$ vs. $3.9 \%$ and $8.7 \%$ vs. $0 \%, P<0 \cdot 001$ ). AGI resulted in 8891000 days of absence from school or work per year nationally (95\% CI 6009 000-12 780 000).

\section{Economic impact}

Between November 2013 and November 2014, AGI cost $€ 814099000$ (range $€ 583214000-€ 1045000000$ ) to society in productivity loss, of which $64 \%$ was incurred by time away from employment due to the individuals' symptoms, the rest by caring for sick children. AGI-attributable healthcare usage cost $€ 191785000$ (range $€ 171095000-€ 212213000$ ), of which GP usage accounted for $19 \%$. The overall cost of AGI for Sweden was $€ 1005885000$ (range $€ 754309000-€ 1257195000$ ), corresponding to a cost per case of $€ 294$ (range $€ 221-€ 368$ ).

\section{DISCUSSION}

This study combines a prospectively measured incidence rate of AGI with an estimation of its perceived severity, associated healthcare usage and societal and economic impact. It provides information that cannot be ascertained from traditional surveillance data, and illustrates AGI's high societal and economic impact. According to our results, in 2013-2014 in Sweden, there were 3351000 domestically acquired AGI episodes, leading to 238000 GP consultations, 62000 hospitalizations and 8891000 days of absenteeism, costing $€ 1005885000$. The AGI incidence may be underestimated by excluding the first 3 weeks of the study, which coincided with a period of high AGI activity, although the effect on overall incidence is likely to be small. This cost is likely an underestimate of the total cost of AGI to society, since it excludes the cost of cases acquired abroad, as well as the productivity loss attributable to the long-term sequelae of AGI, which can exceed the cost of acute morbidity [23]. We have used the human capital approach to estimate the cost of production loss. This approach has been used by other studies estimating the production loss associated with AGI $[11,12]$. Using another approach, such as the friction costs method (cost of lost days until another individual replaces the sick 
individual) would generate a different result, in general a lower estimate of the total cost. However, with a disease that is not chronic and does not generate long-term sick leave the friction cost method is less applicable and may result in higher estimates than the human capital approach.

Compared with AGI estimates from other cohort studies $[1,5]$ our incidence is higher. The incidence may be underestimated as the denominator of the incidence calculations did not exclude time spent abroad, although the overall impact on incidence is likely to be limited. In addition to reflecting true differences in community incidence, the difference could be explained by the fact that our cohort was sampled from the whole population, rather than a GP-registered population. In addition, participants may have been more likely to report compared with studies requiring participants to submit stool specimens, which can be perceived as a barrier to reporting. In one UK study, when both definite and possible cases were included, the AGI incidence increased to 523/1000 person-years [1], higher than the Swedish AGI incidence estimate. A study estimating AGI incidence in Sweden using a different methodology obtained a similar estimate, validating our result [14]. It is also possible that the overall AGI incidence has increased since cohort studies with a similar methodology were carried out in The Netherlands and the UK (1999 and 2009); in the UK, AGI incidence increased by $40 \%$ between the mid-1990s and 2009 [1].

The estimated incidences in Norway and Denmark, neighbouring countries with comparable sociodemographic features, were much higher [7, 9]. This could reflect a true difference, differences in study design or the fact that these studies were based on small samples.

The higher incidence in children aged $<5$ years, the seasonality, and the median duration of an episode in our study were compatible with the published literature [1, 5-7]. Although AGI has been described in the literature as self-limiting and of low severity, in Sweden, only a minority of individuals experiencing AGI described the episodes as mild. It is possible that the delay between reporting symptoms and receiving the severity questionnaire may have biased the results towards more severe episodes as these are likely to be recalled more accurately. This study captured self-perceived severity only, yet the episodes perceived as severe lasted longer and resulted in more healthcare use than mild episodes, thus supporting the higher severity claim. We could not ascertain whether any of the cohort participants had died, which may underestimate the proportion and economic impact of very severe cases. This limitation is inherent to a cohort reporting online, unless the cohort can be linked to other data sources. In our case, this was not possible as we did not have access to the participants' identity.

In agreement with other studies [11, 12], we found that productivity loss is a major driver of the societal cost of AGI. Compared with other countries, the cost per case in Sweden may be high for two reasons: first, salaries are high and inflated by high social fees: in 2012, the average cost of a day's work for individuals aged 20-64 years in Sweden was SEK 1579 (€175), compared with AUD175 (€120) in Australia in 2006 [12] and 101 GBP (€126) in the UK in 2012 [24]; second, healthcare costs are high: a GP consultation in Sweden cost SEK 1424 (€157) in 2014, compared with 45-66 GBP (€56-82) in the UK in 2013 [25].

We were unable to adjust for the fact that individuals may have stayed at home due to their own sickness as well as caring for a sick child at the same time. Furthermore, the proportion of sick children aged 1-5 years, with parents on parental leave with a younger sibling, is also unknown. In many instances, however, participants reported 0 days off work if they or their child were sick but they were already at home for other reasons (such as parental leave). These uncertainties around the exact number of days off should not greatly impact the total cost. Since most AGI does not require a medical prescription [1], we excluded individual costs for medication together with travel to care. These costs are small compared with productivity loss, and therefore unlikely to impact the overall cost.

Hence, overall we likely underestimated the societal economic impact, yet our estimate provides an informative indication of the magnitude of the economic impact of AGI in Sweden.

The proportion of AGI cases seeking healthcare was low compared with other high-income countries $[1,6,7,10]$, but the proportions of AGI cases attending primary care and hospital were comparable to another estimate of AGI-related health-seeking behaviour in Sweden [14]. Patterns of healthcare use are dependent on country-specific healthcare-seeking behaviour and healthcare system characteristics, which may account for some of the differences. It is also possible that organisms with a more severe aetiology, leading to higher consultation and hospitalization rates, have a lower incidence in Sweden. Finally, 
we cannot exclude that some hospitalized cases were unable to report their illness.

Of the participants, the proportion reporting weekly was high, relatively constant, and did not decrease over time. This indicates that, although the proportion of the general population willing to participate in a regular active reporting system is low, those that do are dedicated and reliable.

Unlike other comparable studies, we did not exclude participants with chronic gastrointestinal conditions, nor did we specifically ask participants not to report symptoms they could attribute to a non-infectious cause such as alcohol consumption. This could lead to overestimating AGI incidence. However, the question, worded in Swedish, implied that people should report when $(a)$ the symptoms were unusual for them and $(b)$ they resulted from being ill, rather than another external cause. The wording of the question should therefore have minimized overestimation by counting symptoms due to these causes. The cohort differed from the population in terms of age distribution. In particular, children were oversampled as a result of the difficulty in recruiting children in previous cohorts in Sweden. In this instance, the response rate in children aged $<5$ years was higher than expected, leading to this age group being overrepresented. This was adjusted for using post-data collection age-calibration.

Participation in the cohort was restricted to individuals up to the age of 85 years who had an email address, since Hälsorapport did not offer an alternative alternative to online reporting. With an internet penetration rate of $94 \%$ in 2012 , the third highest in the world [26], Sweden is a suitable setting for an online only reporting system. Nonetheless, the exclusive use of online reporting may have underestimated AGI incidence in the older age groups who are less likely to regularly use the internet, especially those aged $>75$ years [27].

In conclusion, we have estimated the incidence of domestically acquired AGI in Sweden and its impact in terms of absenteeism and cost. AGI requires substantial healthcare resources and has a high associated cost, mainly due to productivity loss. In spite of the majority of cases not seeking care, people with AGI do not perceive it as a mild illness. Although the exact figures are country-specific, these findings may be relevant to other countries as an indicator of the magnitude of AGI-related costs or to benchmark their own calculated costs. In light of these findings we suggest that (i) public health agencies consider the wider societal impact of AGI when setting public health priorities; (ii) authorities in the food, healthcare and education industry continue to adhere to and enforce infection control standards in order to decrease the burden of disease; and (iii) wider societal costs, including costs for the individual, are taken into consideration when assessing cost-effectiveness for vaccines to reduce the AGI burden of illness.

\section{SUPPLEMENTARY MATERIAL}

For supplementary material accompanying this paper visit http://dx.doi.org/10.1017/S0950268816000467.

\section{ACKNOWLEDGEMENTS}

We thank the Swedish Civil Contingencies Agency (MSB) for funding this project.

\section{DECLARATION OF INTEREST}

None.

\section{REFERENCES}

1. Tam CC, et al. Longitudinal study of infectious intestinal disease in the UK (IID2 study): incidence in the community and presenting to general practice. Gut 2012; 61: 69-77.

2. Roberts JA, et al. The study of infectious intestinal disease in England: socio-economic impact. Epidemiology and Infection 2003; 130: 1-11.

3. Hall AJ, et al. Incidence of acute gastroenteritis and role of norovirus, Georgia, USA, 2004-2005. Emerging Infectious Diseases 2011; 17: 1381-1388.

4. Tam CC, Rodrigues LC, O'Brien SJ. The study of infectious intestinal disease in England: what risk factors for presentation to general practice tell us about potential for selection bias in case-control studies of reported cases of diarrhoea. International Journal of Epidemiology 2003; 32: 99-105.

5. de Wit MA, et al. Sensor, a population-based cohort study on gastroenteritis in the Netherlands: incidence and etiology. American Journal of Epidemiology 2001; 154: $666-674$.

6. Baumann-Popczyk A, et al. Incidence of self-reported acute gastrointestinal infections in the community in Poland: a population-based study. Epidemiology and Infection 2012; 140: 1173-1184.

7. Kuusi M, et al. Incidence of gastroenteritis in Norway a population-based survey. Epidemiology and Infection 2003; 131: 591-597.

8. Scallan E, et al. Foodborne illness acquired in the United States - major pathogens. Emerging Infectious Diseases 2011; 17: 7-15.

9. Muller L, Korsgaard H, Ethelberg S. Burden of acute gastrointestinal illness in Denmark 2009: a population- 
based telephone survey. Epidemiology and Infection 2012; 140: 290-298.

10. Najnin N, et al. Community based study to compare the incidence and health services utilization pyramid for gastrointestinal, respiratory and dermal symptoms. BMC Health Services Research 2012; 12: 211.

11. Henson SJ, et al. Estimation of the costs of acute gastrointestinal illness in British Columbia, Canada. erratum. International Journal of Food Microbiology 2011; 147: 86.

12. Abelson P, Forbes MP, Hall G. The annual cost of foodborne illness in Australia. Australian Government Department of Health and Ageing, 2006.

13. Tan SS, et al. DRG systems in Europe: variations in cost accounting systems among 12 countries. European Journal of Public Health 2014; 24: 1023-1028.

14. Hansdotter FI, et al. The incidence of acute gastrointestinal illness in Sweden. Scandinavian Journal of Public Health 2015; 43: 540-547.

15. Deville JC, Sarndal CE. Calibration estimators in survey sampling. Journal of the American Statistical Association 1992; 87: 376-382.

16. Koopmanschap MA, Rutten FF. A practical guide for calculating indirect costs of disease. Pharmacoeconomics 1996; 10: 460-466.

17. Statistics Sweden. Income from employment by region, gender, age and income bracket, 2000-2012 (http:// www.statistikdatabasen.scb.se/pxweb/sv/ssd/START HE_HE0110_HE0110A/InkAvTjanst/?rxid=9bf53fe66eb6-436c-b282-f13d3bdc1ac9). Accessed October 2015.

18. Swedish Parliament. Law on parental leave (Föräldraledighetslag). 1995: 584. 1995 (http://www. riksdagen.se/sv/Dokument-Lagar/Lagar/Svenskforfattn ingssamling/Foraldraledighetslag-1995584_sfs-1995-584/). Accessed october 2015.

19. Swedish National Agency for Education. Statistics on pre-schools, 2014 (http://www.skolverket.se/statistik-och- utvardering/statistik-i-tabeller/forskola). Accessed October 2015.

20. Swedish Social Insurance Agency. Regulation on temporary parental benefits and care of a sick child (VAB) (http://www.forsakringskassan.se/privatpers/foralder/bar net_sjukt/om_vab/vab_tolv_Ar/). Accessed October 2015.

21. Swedish National Board of Health and Welfare \& the Swedish Association of Local Authorities and Regions. Open comparison of Health Care, 2013 (http://www. socialstyrelsen.se/Lists/Artikelkatalog/Attachments/19238/ 2013-12-1.pdf)). Accessed October 2015.

22. Southern Region Health Board. Prices and reimbursments for Southern healthcare region 2014 https://www.skane. se/Upload/Webbplatser/Sodra\%20regionvardsnamnden/ prislista/2014/helaprislistan2014.pdf). Accessed October 2015.

23. Mangen MJ, et al. Cost-of-illness and disease burden of food-related pathogens in the Netherlands, 2011. International Journal of Food Microbiology 2015; 196: 84-93.

24. Office for National Statistics. Annual survey of hours and earnings, 2013 provisional results (http://www.ons. gov.uk/ons/rel/ashe/annual-survey-of-hours-and-earnings/ 2013-provisional-results/stb-ashe-statistical-bulletin-2013. html). Accessed October 2015.

25. Personal Social Services Research Unit. Unit costs of health and social care 2013 (http://www.pssru.ac. uk/project-pages/unit-costs/2013/index.php). Accessed October 2015.

26. World Bank Data. Internet users per 100 people, 2014 (http://data.worldbank.org/indicator/IT.NET.USER.P2? order=wbapi_data_value_2012+wbapi_data_value+wb dapi_ata_value-last\&sort=desc). Accessed October 2015.

27. Findahl O. Swedes and the internet 2014. An annual study of the Swedish people's internet habit. (http://en. soi2014.se/). Accessed December 2015. 